\title{
OS POEMAS AGRESTES DE GERALDO VALENÇA
}

Adilson Guimarães Jardim ${ }^{1}$

Resumo: Poeta pernambucano que estreou nos anos 40, sem pertencer a nenhuma vanguarda, mas transitando entre algumas delas, sob influência da retomada dos esquemas métricos isossilábicos e de formas como o soneto, com temática regional, Geraldo Valença dá prosseguimento a certos diálogos entre a modernidade e a pós-modernidade, como o tema da identidade e dos espaços: totalitários no primeiro e fragmentados no segundo.

Palavras-chave: Geraldo Valença, Poesia pernambucana, Regionalismo, Modernismo, Pós-modernismo.

Resumen: Poeta pernambucano cuyo estreno se verificó en la década de los 40 del pasado siglo, sin formar parte de ningún grupo de vanguardia pero transitando por algunos de ellos, y bajo la influencia de la retomada de los esquemas métricos isosilábicos y de formas como el soneto, con temática regional, Geraldo Valença da proseguimiento a ciertos diálogos entre la modernidad y la posmodernidad, como el tema de la identidad y de los espacios: totalitarios, en el primer caso, y fragmentados en el segundo.

Palabras clave: Geraldo Valença, Poesía pernambucana, Regionalismo, Modernismo, Posmodernismo.

Os "poemas agrestes", citados no título, além de apontarem na direção de uma temática recorrente na obra de Geraldo Valença, revelam uma condição mesma, como se pretende provar aqui, do processo criador e da relação do poeta com seu ofício. No que toca neste último ponto, principalmente, comentar sobre uma "atividade poética", à primeira vista, supõe analisar um artista ininterrupto no seu ofício, com uma poesia vasta em quantidade e uma presença constante no meio literário.

Entretanto, a constância de Geraldo Valência é bem diversa. Ele não publicou muito, é bem verdade. Encaixa-se naquela categoria de poetas que Vinícius de Moraes batizou e que Manuel Bandeira popularizou, a de "poetas bissextos". Nunca procurou a notoriedade, mas, à sua maneira, soube se manter fiel à Poesia, sacrificando a "quantidade em favor da qualidade", como foi dito certa vez a seu respeito pelo poeta Edmir Domingues ${ }^{2}$, artista contemporâneo de Valença e seu amigo. Foi aquele "cultivador de letras e silêncio", nas palavras de Mauro Mota³, que em

1 Mestre em Teoria da Literatura pela Universidade Federal de Pernambuco (UFPE). Este artigo foi apresentado no Centro de Artes e Comunicação, durante a segunda edição do seminário Literatura em Curso, organizado pelo Departamento do curso de Letras da citada universidade, em 2005. Endereço eletrônico: Adilson_jardim@yahoo.com.br

2 Apud DOMINGUES, Edmir. Prefácio In A rosa total, 1989.

3 MOTA, Mauro. O poeta no cartório, 1967. 
um distante 1967 já se queixava da ausência do jovem artista, o "irmão Geraldo", nas suas palavras. De fato, lembrou-se o autor deste artigo de um acontecimento curioso, ocorrido nos corredores da universidade que freqüentou durante muitos anos: ao buscar informações sobre Valença, junto a uma professora da casa e poeta recifense, conhecedora da poesia pernambucana, a única resposta obtida foi outra questão lançada: "É o juiz?" Sim, tratava-se do mesmo homem de comarca, e aquele epíteto pareceu uma sentença desfavorável ao poeta - uma imagem de um homem de toga, encerrado nos gabinetes pouco poéticos da burocracia forense. Em parte, talvez, culpa do poeta, que não gostava de público. Considerando a ignorância apresentada, inclusive pela ilustre professora, pretende-se em seguida apresentar uma breve biografia de Geraldo Valença (ainda que Octavio Paz tenha achado mais pertinente iniciar a biografia de qualquer poeta por seus poemas), para efeito de contribuição a futuros pesquisadores ${ }^{4}$.

\section{Primeiro Percurso}

Geraldo de Souza Valença é natural de Pesqueira (sertão pernambucano), nasceu a 8 de maio de 1926 e logo se transferiu com a família para São Bento do Una, cidade do agreste do mesmo estado. Passou toda a infância nessa terra, onde cursou o primário, mas completou o segundo grau no Recife, aí obtendo também o título de bacharel pela antiga Faculdade de Direito. Primo de Gilvan Lemos, segundo informações do senhor Rubem Valença, irmão mais novo de Geraldo, e tio do compositor Alceu Valença, que gravou soneto seu, intitulado Eu sei que é junho, o poeta estreou, literariamente, em 1946, ainda no primeiro ano de faculdade, quando foi apresentado por Alfredo Pessoa de Lima, através do artigo A poesia também corre nas águas do Rio Una, pelo Diário de Pernambuco. Logo se aproxima de outros artistas, como Ariano Suassuna, Audálio Alves, Edmir Domingues, Mozart Lopes Siqueira e Mauro Mota, enquanto lia Manuel Bandeira, Antonio Nobre, Garcia Lorca, entre outros que influenciaram sua geração. Em 1960, entra em contato com o grupo de $O$ Gráfico Amador, movimento editorial pernambucano, fundado por Aloísio Magalhães, José Laurênio de Melo, Gastão de Holanda e Hermilo Borba Filho, entre outros, que participavam ativamente ou colaboravam com o movimento. Através de $O$ Gráfico, veio à luz o primeiro (e quase único) livro de poemas de Geraldo Valença, A rosa jacente. Trata-se de uma pequena brochura de cinqüenta e duas páginas inconsúteis (não costuradas), contendo 22 poemas, com ilustrações de internas de Adão Odacyr Pinheiro e publicada no parque gráfico da Editora do Recife, com o selo de $O$ Gráfico. Embora publicando textos nos suplementos do Diário de Pernambuco, o próximo livro só vem à luz em 1989, na realidade uma reedição de $A$ rosa jacente, que foi dividida em duas partes e acrescida de

\footnotetext{
4 Citado de memória.
} 
novos textos (dezenove aos vinte e dois originais), sob o título de $A$ rosa total, através da editora Belo-Belo, de Maria de Lourdes Hortas. Com novas ilustrações somadas, dos artistas Maurício de Castro Filho e Fernando Florêncio (bico de pena para a contracapa), A rosa total é fruto de uma atividade lenta, porém incessante de seu autor, que figura ainda em algumas antologias, como a dos Poetas da Rua do Imperador, além de revistas e periódicos ${ }^{5}$. Faleceu no Recife em 13 de junho de 1991, vítima de câncer.

\section{SEgundo PERCURSO}

Da leitura dos versos desse artista, contempla-se uma poética que nasce e se desenvolve sob a emergência da memória. Vazio saturado de branco. O branco das pedras, das colinas, do sol e da paisagem agreste de sua infância; e o branco da memória, cujas imagens vão se tornando evanescentes, e pouco a pouco transformando essa paisagem enquanto a remonta com suas lembranças. Ao analisar Em busca do tempo perdido, de Marcel Proust, Walter Benjamin ${ }^{6}$ chamou a atenção tanto para o problema da transformação radical do passado, sempre que se procura por ele, como da importante relação que ele mantém com o presente, dando-lhe significado e remodelando-o a todo o momento. Com isso, já se reflete aqui a postura de Geraldo Valença diante dos temas de sua poesia e do posicionamento crítico que assume diante do seu tempo.

Talvez o termo mais adequado para definir a poesia de Geraldo Valença seja a palavra "resistência", tal como é pronunciada por Alfredo Bosi, a que visa a "recuperação do sentido comunitário perdido" ". Longe sim, de se tratar de algum revanchismo retrógrado e passadista, mas contra as idéias de certas posturas anticentralizadoras, que a cada momento redefinem violentamente as margens de todos os velhos discursos, como têm se comportado as novas teorias pósmodernistas. Um dos aspectos negativos do discurso pós-modernista, melhor dizendo, "dos discursos", no plural, é que eles só conseguem produzir, uma vez iniciada a festa, um amontoado de práticas discursivas litigantes, que ora abraçam a causa de uma literatura engajada, politiqueira, avacalhada, ou naïf, para ser politicamente correto; ora arremessam para além do inaceitável autores e obras que não se ajustam às suas lentes míopes, melhor seria (além de mais adequado) se fossem estrábicas. Assim, da noite para o dia, Melville se torna um anti-ecologista - odioso inimigo da eco-crítica, mais novo braço de rio das teorias pós-modernas; Shakes-

5 Mencione-se aqui outro artigo deste autor na revista Tambor, n. 2, 2003, da Fabeja, Belo Jardim, além da dissertação dedicada ao poeta: O espaço lúdico na poesia de Geraldo Valença (2007).

6 BENJAMIN, Walter, 1994.

7 BOSI, Alfredo. O ser e o tempo da poesia, 1990, p.144. 
peare um misógino, Machado de Assis, pouco engajado na causa abolicionista, como observou Leyla Perrone-Moisés ${ }^{8}$. Os biógrafos de plantão analisam Pedro Nava e Mário de Andrade pelos aspectos polêmicos de sua sexualidade. Diante de um quadro constrangedor como esse, pode-se especular aqui as precauções de Geraldo Valença, ao optar pela discrição.

Retornando às pedras, ou aos poemas agrestes de Geraldo Valença, mencionem-se aqui dois outros rótulos, ou melhor, duas palavras igualmente proscritas em meio às teorias atuais, mas que se acredita, nesta comunicação, poder aplicar-se à poética do autor de $A$ rosa total: seriam elas "regionalismo" e "nostalgia", que implicam uma mirada para a modernidade ainda inquietantemente aberta, cujos pressupostos já foram abordados nas visões revisionistas de teóricos como Fredric Jameson e Terry Eagleton. Não se pode negar que as mudanças significativas ocorridas nas sociedades industrializadas no último século, o inchaço das grandes cidades, e o fluxo contínuo de imigrantes e informações, provocaram mudanças sensíveis nas relações interpessoais, bem como no modo de vida das pessoas. Mas não se pode atribuir que houve uma mudança completa e homogênea em escala global. Aquelas comunidades, para quem tais mudanças significaram menos um convite para participar de um progresso anunciado, do que novos tipos de apartheid, apenas assistiram, incomodadas, à acentuação da idéia de uma outridade menos privilegiada; alienígenas e estranhos, a quem muitos só desejam avistar na condição de turistas.

\section{Terceiro Percurso}

Analisar a poesia de qualquer autor em termos regionais, entretanto, significa menos assumir uma postura retraída e provinciana, do que reconhecer a manutenção das expressões e valores locais, a existência de variações dentro de um todo cultural. Regionalismo não no sentido de comunidade presa em um tempo e um espaço cerrados e imutáveis em valores e modos de vida, excessivamente unificada, mas com o sentido positivo de "lar", referência primeira e permanentemente recorrente do indivíduo; um tempo humano, tempo da memória, como registrou Eduardo Lourenço ${ }^{9}$, aquele que escapa aos relógios e aos mapas. Um retorno a um lar que só encontra paralelo com o próprio corpo, aquele espaço estável e irredutível do ser, como afirmou Michel Foucault ${ }^{10}$, espaço de resistência contra toda forma de opressão.

Poder-se-ia também partir de princípio diverso para analisar essa condição agreste dos poemas de Geraldo Valença. Mas se advertirá apenas que, "nostalgia”, tem na sua base etimológica a "dor do regresso". Não é de se estranhar que de

8 Cf. Altas literaturas, citado de memória.

9 Cf. Revista CULT, n. 27, out. 1999.

10 Apud HARVEY, David. Condição pós-moderna, 1992, p. 196. 
tempos em tempos, veja-se revitalizado um hedonismo entre as pessoas, após mudanças bruscas que ocorrem nos grandes centros, quando os corpos se entregam, entorpecidos, ao balanço de raves, desnudos em praias especializadas para esse tipo de turismo ou erotizados em casas de swing. Análises mais extensas, a partir de tais fenômenos sociais, poderiam explicar as causas desse regresso dramático na ordem do simbólico, que costuma se manifestar como uma espécie indistinta de localismo, o retorno a um "lar" qualquer.

A poética de Geraldo Valença, enfim, à maneira de bússola, incita os leitores a rever sua posição nos espaços, numa perspectiva social e simbólica. Ao abandono do corpo dentro da amplidão da Grande Cidade, o poeta volta-se para o espaço natural oposto ao urbano. Em tempo: uma rápida consulta a um dicionário forneceu as seguintes equivalências para a palavra "urbano": "afável", "bem-criado", "bem-educado", "civilizado", "cortês"11. O modo de prescrição de regras de comportamento aí sugerido nessa primeira palavra poderia conduzir naturalmente a interpretações negativas na oposição entre "urbano" e "rural". Mas diante desse jogo de forças contrárias, Valença reconstrói com seus poemas o espaço rural como ambiente diverso ao imaginado pela reflexão urbana e mesmo complementar a seu espaço supostamente íntegro. O senso de territorialidade do poeta indica um lugar de sonho ou utopia, que a partir de certos signos, repleto ainda daquelas imagens persistentes do "natural", "espontâneo", do "atemporal", do "lugar-sempreo-mesmo", promove um intercâmbio com os signos hostis que regem o cotidiano da Grande Cidade.

O tema presente ao longo de seus versos é o do indivíduo oprimido pelo sistema, que não consegue adaptar-se ao ambiente e à cultura dos "bem-criados". Assim, veja-se o trecho um primeiro poema do autor, intitulado Bem, obrigado:

Cumprido estágio

Do sono, venho

Perante vós,

Provar o engenho:

- Bom-dia, pai

— Bom-dia, amada

Ninguém recusa

Mão estirada

O que se escalou

Parede de ontem

(Penso comigo)

Não se estragou

Espadachim,

Corto a gilé

11 Dicionário Gamma, 198[?]. 
O outro que em mim

Faz finca-pé

Experimento,

Agora, a mão,

$\mathrm{Na}$ briga alegre,

Talher e pão

Boto a gravata,

Aperto o nó

Enforco (penso)

O homem só

Gerente alegre,

Me retribuo:

Suo e, depois

Lavo o que suo

E vou, e vou

Rodar bengala

Que engenho firme

Não se estragou

No canto da

Boca, o palito,

Como um apito

Que se calou

Entro na rua,

Com meu refrão

De saudação

Ao paletó

Aço também

Se gasta (penso)

De leve, passo,

$\mathrm{Na}$ face, o lenço

Menos o morto,

Mais o jornal:

- Sétimo dia,

$\mathrm{Na}$ catedral

Ninguém é dono

De si? Então,

Por que me querem

Tomar a mão?

Ao meu vizinho,

Duro fiscal,

Mostro meu riso,

Tempo feudal... ${ }^{12}$.

12 VALENÇA, Geraldo. A rosa total, 1989, p.15. 
De princípio, percebe-se, nesse texto, um duplo movimento, o primeiro, na ordem do ritmo e da cadência dos versos, orquestrados por uma métrica homogênea, isossilábica, em tetrassílabos e rimas agudas, que já remete àquela opção do poeta referente ao processo estético ou ao de criação que foi mencionado no início deste artigo, que se mantém fiel a certas estruturas versíficas tradicionais, àquele “esforço necessário" comentado por João Cabral de Melo Neto ${ }^{13}$, um resistir sem implicâncias aos versos livres, para a integridade de seu próprio estilo. $\mathrm{O}$ segundo movimento é da ordem das imagens. As mãos deslocam-se freneticamente para várias direções e com múltiplas intenções e utilidades, de acordo com cada situação, e se estendem para repetir o gesto cortês obrigatório, na mesma medida em que se retraem no gesto brusco da defesa. Em um momento, se avista o gesto espontâneo e despretensioso do "rodar bengala", à maneira de Carlitos, figura homenageada pelo poeta em outro dos poemas de $A$ rosa, como um arquétipo da rebeldia irreverente ao sistema, a personagem que em um de seus filmes chuta o policial que o quer manter sob vigilância. Em outro momento, a mão reproduz um gesto que mais parece de um verdugo, ao apertar o nó da gravata como se fosse o de uma forca. A imagem do "fiscal" nesse texto é outra constante nos poemas de Valença, e é sempre mencionada nos instantes de opressão ou de restrição dos espaços descritos em cada texto. Note-se que, nesses versos, o poeta "entra na rua", ao invés de sair para ela. Aqui, a rua, ao invés de representar liberdade, demonstra, ao contrário, a imagem de novo espaço comprimido, cheio de indivíduos de gestos maquinais, com apertos de mão já sem significado e isolados em seu vasto anonimato.

Antes de prosseguir, julga-se conveniente insistir que esta leitura dos versos de Geraldo Valença não visa contrapor poéticas citadinas e interioranas, no sentido de mostrar um poeta saudosista, egoisticamente ávido para restituir uma paisagem perdida, que foi da sua infância e a qual ele julga ideal. Longe disso. Ao recompor o tempo, a exemplo de Proust, Geraldo Valença admite tratar-se de um signo semimorto na sua anterioridade de forças. Mas, justamente a exemplo do escritor francês, tal invocação do passado, para o pernambucano, insere-se em seus poemas como promessa de renovação do próprio presente, que já é um passado em aberto. Ao relacionar campo e cidade, o olhar do poeta rejeita o que seria a busca de um tempo mítico, revestindo-se apenas dos valores de que necessita desse passado agreste para compreender melhor um presente igualmente cáustico, aproximandoos por associação e contigüidade.

Assim, nem o espaço rural propriamente dito, nem o espaço urbano, mas um meio-termo entre os dois, uma zona especulativa onde o poeta se perde conscientemente, único lar possível na contemporaneidade. É essa a forma de resistên-

13 In SECCHIN, A. Carlos. João Cabral: a poesia do menos, 1985, p. 303. 
cia de Valença e seu posicionamento crítico dentro do seu tempo: por um lado, o autor recusa o mega-projeto arquitetônico das utopias modernistas, voltadas quase sempre para a malha urbana - verticalidade vertiginosa, aço e vidro, unidade e simetria nauseante das grandes cidades; por outro, não compartilha da "fragmentação" espacial, os nichos sociais e as individualidades limitadas a uma eterna e angustiante relação com o outro, tal como foi erroneamente enxergada pelos teóricos pós-modernistas. Antes, a geografia desse artista produz planos inteiros de uma horizontalidade significativa, porém numa espacialidade diversa, feita de esquinas, cercas (imaginadas pelo poeta não para serem derrubadas a golpes ferozes revolucionários, mas "saltadas" infantilmente); chão batido e pisado por pés descalços, e rios que correm e transbordam cada vez mais fundo do inconsciente. Valença constrói, desse modo, um ambiente lúdico e uma referência primeira que pode recuperar sempre que desejar, aquelas "fixações no espaço" ou "de felicidade", tal como se refere Bachelard ${ }^{14}$; pode, assim, orientar-se no espaço "real" - que, aliás, tornou-se outra palavra proibida dentro da colcha de retalhos pós-kantiana/pósmoderna.

O poeta não busca nenhuma redenção, nenhum paraíso perdido. Mesmo o espaço rural que evoca, ele sabe opressor, pelas relações de poder e desigualdades aí existentes. Nos versos de Valença, a deflagração dessa relação de forças antagônicas, de humildade e humilhação, de descaso e escárnio:

- Me desculpe a ousadia,

Mas a escola da lição?

- Amarelo Zé Maria,

Quem quer vir ensinar ao Cão?

— Me desculpe a ousadia,

Mas o posto da injeção?

- Amarelo Zé Maria,

Quem quer vir tratar do Cão? ${ }^{15}$.

Se as relações de poder e submissão no espaço urbano apresentam-se de maneira velada ou são impostas inconscientemente, no ambiente rural essas mesmas relações são construídas na sua forma mais direta de violência física, psicológica e étnica. É justamente a percepção de tais arbitrariedades ocorridas nesse espaço primário, que permite ao poeta compreender e jogar com os signos de opressão do espaço urbano. Dessa maneira, investigando ambos os espaços simultaneamente, mas considerando as peculiaridades de cada um, nem que seja dentro daquela ordem simbólica de que se vem mencionando aqui, é que o poeta pode fazer do

14 BACHELARD. A poética do espaço, 2003, p. 25.

15 VALENÇA, Geraldo. Op.cit., História de Zé Maria e do Ferreiro (trecho), p. 84. 
próprio território da Poesia aquela fonte de conhecimento, como percebeu Alfredo Bosi ${ }^{16}$. Ambos os espaços se associam e geram imagens poderosas, com as quais o poeta dialoga. Cita-se:

O homem voltou da rua. Ah! como vinha!

Trancou-se mais do que trancara a porta.

Trancou-se. A mesma natureza morta:

O prato, o bife, o hectare da cozinha ${ }^{17}$.

"A mesma natureza morta", extinta ou varrida dos olhos. A cada cômodo da casa, a cada rua percorrida, a cada gesto cortês mecanicamente executado, o reconhecimento de uma paisagem estranha, hostil, agreste no pior sentido da palavra: "baldio", "deserto", "estéril"18.

\section{CONSIDERAÇÕES FINAIS}

Para concluir, sem deixar nenhuma conclusão, recorde-se aqui uma máxima da experiência no campo, de algumas pessoas da Cidade Grande, para quem financiar o sonho do sítio e sua instância bucólica são duas felicidades: quando se compra e quando se vende. São eternos turistas, para quem as cidades e seus arredores significam apenas cartões postais, vistas sempre de longe, com um resumo mal contado no verso, e que em uma primeira impressão sempre parece satisfatório aos fregueses.

Olinda, quinta-feira, 24 de fevereiro de 2005.

\section{REFERÊNCIAS}

BACHELARD, Gaston. A poética do espaço. Trad.: Antonio de Pádua Danesi. 6. ed. São Paulo: Martins Fontes, 2003.

BENJAMIN, Walter. Magia e técnica, arte e política: ensaios sobre literatura e história da cultura. In: Idem. Obras escolbidas, v. 1. Trad.: Sérgio Rouanet. São Paulo: Brasiliense, 1994.

BOSI, Alfredo. O ser e o tempo da poesia. São Paulo: Cultrix, 1990.

HARVEY, David. Condição pós-moderna. Trad.: Adail Ubirajara Sobral e Ma Stela Gonçalvez. São Paulo: Loyola, 1992.

HOLLANDA FERREIRA, Aurélio Buarque; LUZ, José Baptista da. Dicionário Gamma da Lingua Portuguesa. 11. ed. Rio de Janeiro: Civilização Brasileira, 198[?].

LIMA, Guilherme Cunha. Modelo de design gráfico para descrição de livros de arte. Revista Estudos em Design, v. 3, n. 2, dez. 1995.

MONTEIRO, Antônio B. Apresentação. In Poetas da Rua do Imperador. Recife: POOL Editorial, 1986.

16 BOSI, Alfredo. Op. cit.

17 VALENÇA, Geraldo. Op. cit. Relatório do homem (trecho).

18 Dicionário Gamma. Op. cit. 
MOTA, Mauro. O poeta no cartório. Diário de Pernambuco, Recife, Coluna Agenda, $1^{\circ} \mathrm{Ca}$ derno, 23 ago. 1967.

REVISTA CULT. Entrevista com Eduardo Lourenço. São Paulo: Lemos, n. 27, out. 1999. SECCHIN, Antonio Carlos. João Cabral: a poesia do menos. São Paulo: Duas Cidades, 1985. VALENÇA, Geraldo. A rosa total. Recife: Belo-Belo, 1989. 